\title{
LESSON 83
}

MARGINS: Pica, 20-70; Elite, Type this paragraph as many times as your teacher asks.

30-80.

Warm up

Increase Speed

30 wpm 5 minutes.

S35-SI 1.03

Improve Accuracy

25 wpm 5 minutes.

A31 - SI 1.29

Some machines use a ribbon of carbon paper.

Tabulation 31

PAPER: A5 $(210 \times 148 \mathrm{~mm})$.

TARGET TIME: 13 minutes.

Rule up in ink or ball point pen.

UNIT 21
The new paintbox contained all of the colours they had wished for. Azure blue, Aquamarine, Jade and violet were all very striking shades.

Just what do you know of the sea? Not a lot, if, like most of those who live far inland, you go to it once or twice a year for a day or two when a break at work comes or there is a fine day and you want a trip out. But for these brief trips, it is a fair bet that you think of the sea only when you hear some news or read of it in a book or see some film.

For those who live near the sea it means much more than a day out. Such people find that it may not be ignored and it plays a larger part in their lives. The turn of the tide brings with it change of some kind even though it may be just one of its mood. For those who are at work on the sea it may mean a way of life which is timed by the tides and it is said that time and the tide wait for no man.

There are two main types of typewriter ribbon available and you should know what kind would best: suit your requirements. If you only use the black part of your ribbon you would be advised to obtain a black record ribbon, so that as you wore out one side of it you could just turn it over, and use uj) the untouched half. If you need two colours, thell you need to buy a bi-chrome, or two colour, ribbon and these can be obtained in a variety of colours, though black and red are the most common. Ribbons are made of a variety of materials, such as cotton or silk, or nylon. Make sure you know the make of your machine when you go shopping.

\begin{tabular}{|l|l|l|l|l|l|l|l|l|l|l|}
1 & 2 & 2 & 3 & 4 & 5 & 6 & 7 & 8 & 9 & 10
\end{tabular}

